\title{
Development of Participatory Design Processes for Designing Sustainable Urban Park in Indonesia: A Planning Method in Eco-Model Cities of Japan
}

\author{
U Surahman, M S Barliana and J Maknun \\ Universitas Pendidikan Indonesia, Bandung 40154, Indonesia \\ *usep@upi.edu
}

\begin{abstract}
Participatory design projects in major cities of Indonesia became more popular since the mid-1990s, when the Indonesian public administrations changed its systems from the previously strong centralization to the new local self-governance. In most of the public projects that mandated the public participation including in designing urban parks, however, the kinds of participation tended to be at the minimum level, such as holding the required public announcements and public hearings. Therefore, major cities of Indonesia have phenomenon of low use, and abandoned urban parks such as in Bandung City. As the substances of the participatory designs are increasingly in demand these days, it becomes more necessary to provide proper design tools and processes for better communications among the residents and experts. Based on the lesson learned from urban parks in Japan, this paper proposes a practical alternatives of design tool, applied to the three steps in the general participatory design processes. The three steps are 1) public information; 2) design workshop; and 3) feedback. The paper argues, among others, that utilization of appropriate design tools in each step contributes to better communications among residents and experts, which would eventually enhance the mobilization of community spirits among all participants. This paper clarified that Bandung needs to improve the parks by involving community and providing the communal space for participation.
\end{abstract}

\section{Introduction}

Asia Pacific has the characteristic as the most populated in the world with the higher population densities in its major cities. With the high urban growth rate, the public places such as parks, street, and squares become eyes of the city and play the vital roles for urban residents who cannot afford private amenities. Urban parks are the place where almost uniquely, ecological, social, cultural and economic imperatives occurred. It been realized that the parks are valuable for urban sustainability and support quality of life. Therefore, European cities have committed to making the issue of urban parks as focal points for Agenda 21 centuries [1] and both quantity and quality of the parks should become a major goal of the cities [2]. Generally some parks may attract greater use while the other just only the waste place islands of non use, maintained at public expense [3]. Urban parks are the key of most neighborhoods, but sometimes neglected by both local government and surrounding people [4]. This condition can be seen in Bandung City where urban parks suffered with less maintenance and usage. In some cases, people are not conscious that many small parks already shifted into other uses such as

Copyright (C) 2019, the Authors. Published by Redwhite Press.

Page $\mid 57$

This is an open access article under the CC BY-NC license

(http://creativecommons.org/licenses/by-nc/4.0). 
roads, gas stations, and other commerce buildings. People have low relationship and lack sense of belonging with existing parks while local government failed to involve community in planning and management system.

In the context of Asia Pacific countries, Japan is more advanced in urban park system than Indonesia. Tokyo, Osaka and Nagoya as the biggest cities of Japan can be a good practice in its urban parks systems. The community's involvement becomes an important factor for attractive and high use parks. In the effort to provide the greening to the city, foster healthy and active lifestyle, and bring people together in the neighbourhood, local park's function should be maximized to fulfilled the need of people together in harmony with create more ecological benefits. Since many local parks in Bandung have similar size with block parks in Japan, Bandung could improve the park management system by taking some experiences from cities of Japan.

To provide better processes and products in participatory designs, the communication among residents and experts is one of the most important matters. Existing studies point out that expertoriented design tools are obstacles for active residents` participation [5]-[7]. This study concerned with the lesson learned from best practices of urban parks system in Japan. The paper argues, among others, that utilization of appropriate design tools in each step contributes to better communications among residents and experts, which would eventually enhance the mobilization of community sprits among all participants, and proposes an alternative design tool, targeting three steps in design processes.

\section{Methodology}

\subsection{Condition of urban parks in Bandung City}

Bandung City is the capital city of West Java has special territory enjoying the status of the province. It located in the middle of West Java and its centre of government, commerce and industry with very rapidly city development. The provincial administration of Bandung divided into 5 regions, Bandung Pusat (Central Bandung), Bandung Utara (North Bandung), Bandung Selatan (South Bandung), Bandung Barat (West Bandung), Bandung Timur (East Bandung). The Bandung's census on 2018 reported that more than 3 million people resided in Bandung with a population density of 15,713 people per square kilo meters and it will be more crowded in the day [8].

As megapolitan city, Bandung has an insufficient number of urban parks even though data from Department of Park and Funeral of Bandung shows the trend of increasing park per year. In the middle of citizen's demand to add more green space area in the city, the fact is many existing urban parks are not well maintained, less usage, and unloved particularly small parks in neighbourhood area (Fig. 1).

(a)
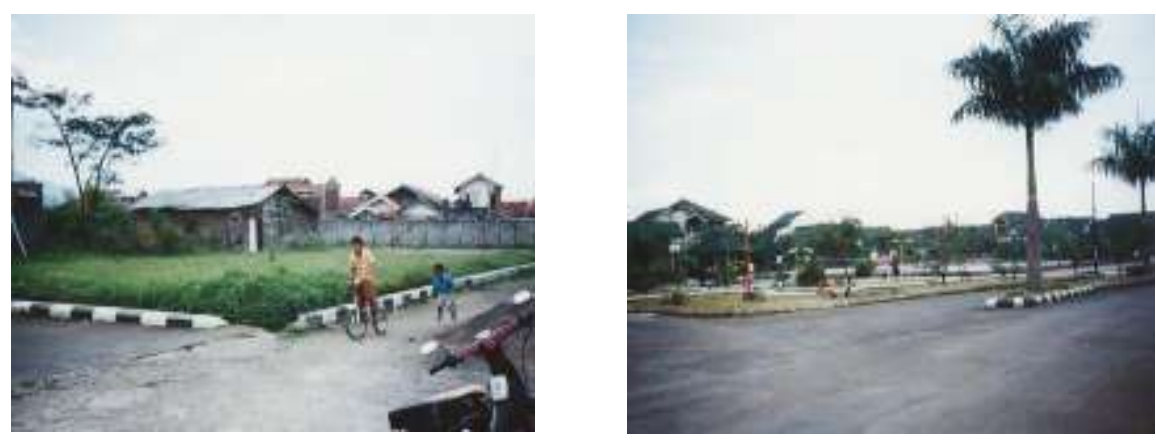

Figure 1. The Condition of urban parks; (a) Neighborhood area, (b) City centre 


\section{RedWhiteperess Gilobal Conferenees Series: Sciences and Technology (GCSST), Volume 3, 2020}

\subsection{Urban parks}

Francis [4] defined that existing parks less than 5-6 acres (2-2.4 hectares) called small parks and they included basic and neighbourhood parks. As a key part of most neighbourhood, small parks mostly recreational benefits, and represent the most accessible and democratic fragment of nature in an urban setting [9]. However, sometimes small parks are relegated to the status of stepchild of municipal and metropolitan open space system [4]. Previous studies affirmed that certain populations perceived to be less likely to use public parks in neighbourhood level than in larger parks [3]. Some parks just as wasteland that is not attractive enough for people to visit and spend their time to enjoy the nature or engage with community. Less usage becomes one of the park issues that need further thinking how to maximize every single public expense for community benefits.

As the subject of this paper, people's involvement believed can increase the sense of belonging among people, to public space and increase the degree of neighbourhood attachment. In case of park, people are likely to participate if parks are 1) identifiable rather than boundary community, 2) small and have clear local identity than park for the whole city, 3) varied and have clear potential to appeal different interest, and 4) park overlooked by housing and used as a short cut [9]. Park with good management will be high attendance, life and utilized by the users. Therefore, park managers should be maximizing the values of parks for community benefits.

\subsection{Participatory design process}

As for the attributes of design tools in participatory projects, it is necessary to understand what the design processes are about. Among others, Barton, [10] provided 7 steps for shaping neighbourhoods, and [11] suggested a scenario to reuse derelict areas. Urban Action Network [12] also generalized the process of the Neighbourhood Park Movement. Based on them, the general processes of participatory design could be charted as seen in Figure 2.

As seen in the Figure. 2, the general steps in the participatory design processes share common characteristics and assignments, such as taking action and implementation. This paper specifically examines the three steps, which are 1) public information, 2) design workshop, and 3) feedback. These three steps are critical especially for the improvement of communication among residents and experts. This study has been done by doing field observation, study literature, and interview with stakeholders in both Bandung and Nagoya City. We did an interview with local government, local leaders, and some residents $(n=100)$ to examine the efforts to achieve the attractiveness and high use parks, community participation in the park and neighbourhood, kind of problems and desires for park improvement in the near future planning. 


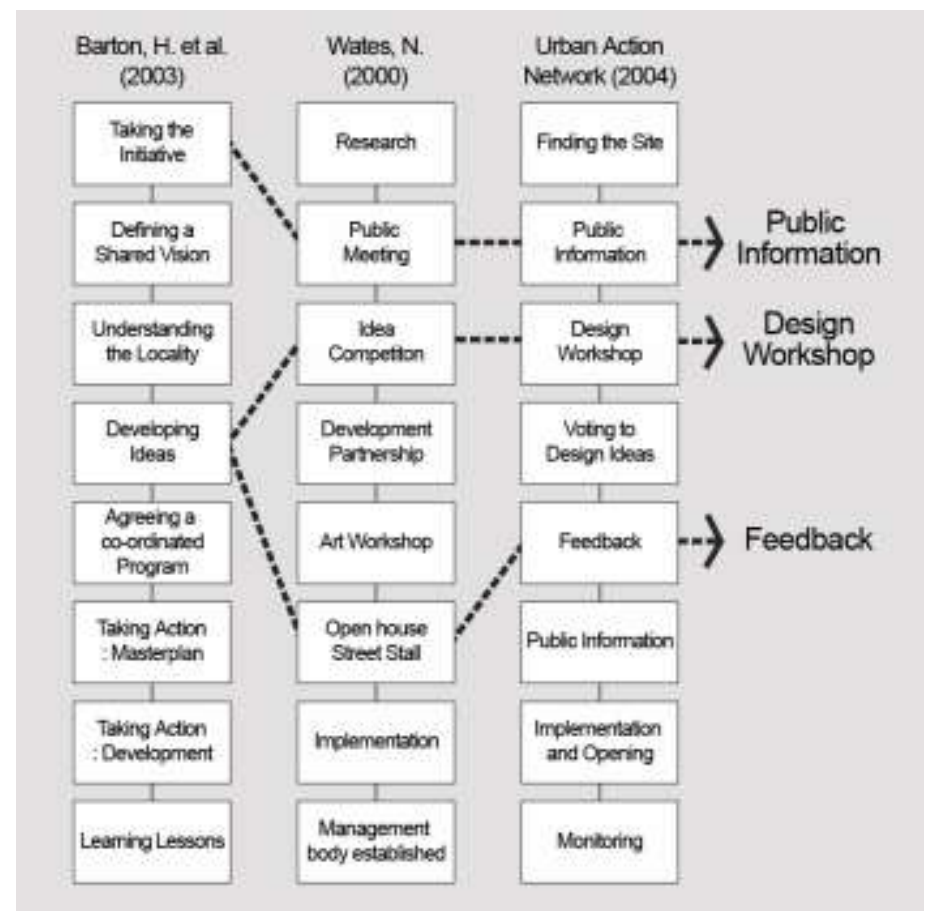

Figure 2. Processes of participatory design

\section{Results and Discussions}

\subsection{Usage and community participation in urban parks of Bandung City}

Field observation in the high income neighbourhood of Bandung City showed that most of park visitors were not the residents but outsiders. The residents of the low income neighbourhood use parks more frequently than high income people. They also enthusiastic to use park with their children or together with their friends. Some respondents stated that they do not involve in any park management except in neighbourhood cleaning day once in a month. In other way, they could participate by collecting the money to pay park's staff to clean more often. Questionnaires result showed that many factors such as cleaning, lack maintenance, safety concern and condition of children playground were the top lists that should be concerned (Fig. 3). Those factors also affected the level of park satisfaction in Bandung City (Fig.4).

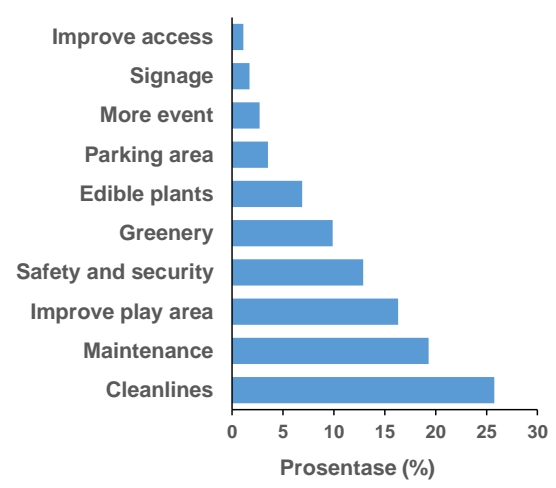

Figure 3. Park use constraint

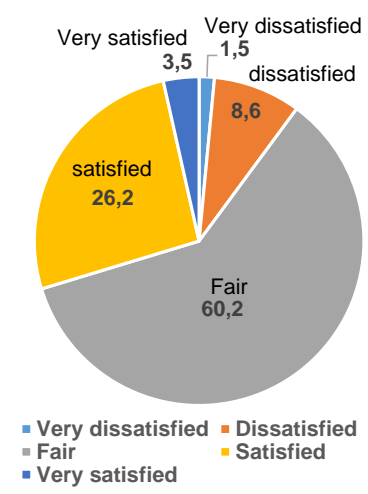

Figure 4. Park user's satisfactiom 
Interview with local leaders and local government indicated that there was the lack of coordination and cooperation to maintain the local park. Even the small parks existed in the residential area, but residents still depended on local government to manage their local parks. Local government had argued that those problems caused of lack of budgets through the years, lack of operational staffs and low awareness of people. Government of Bandung mainly focuses with parks in the main roads or protocol areas rather than spend more budgets to maintain parks in the neighbourhood. Besides that, local government chose to over hand the management to the third parties. From the interview, we found that residents are not directly involved in maintaining the parks but they collect the money and then give it to park staff for taking care the parks. In fact, questionnaire results showed that the residents of Bandung City have high interest to manage the parks. Therefore, Bandung City may need the system that able to facilitate people's demand for participating in park management.

\subsection{Lesson learnt from park management system in Nagoya City, Japan}

Nagoya is the largest city in the Chubu region of Japan. It has been known as the third-largest incorporated city and the fourth-most-populous urban area. It is located on the pacific coast on central Honshu and capital of Aichi Prefecture. Nagoya is covering the area of 326.45 square $\mathrm{km}$. The Nagoya City includes 16 wards and has population in 2010 more than two million people resided in this city with a population density of 6,923 people per square kilometres [13].

As one of the 50th largest urban areas in the world, Nagoya City known as a major industrial area, serving as a port and a "bedroom community" for people who commute to Osaka and Tokyo for work. Similar with Bandung City, Nagoya also suffered with environmental problems and less greenery because of rapid development of factories, modern buildings, and other built areas.

Nagoya City has realized that people power and creativity are the keys toward a wonderful and attractive city. The cooperation among the citizens, organizations, and authorities of the city to work together in the city's development had supported since the first Nagoya General Plan in 1973. The advanced and innovative policies such as environmental strategies through citizens' participation have resulted the city had selected as an "Environmental Model City". This has pioneered environmental action by cooperating with citizens, to protect the environment at all levels ranging from the daily life to the urban and global environment. In general, the three steps in the participatory design processes in designing urban parks in Nagoya are as follows:

Step 1: Public information

The Public Information step was arranged to inform residents of the project in efficient and enjoyable ways. Two design tools were used here, which were problem puzzle and model kit for park design. Problem puzzle showed the participants various pictures of the neighbourhood to inform the problem around the site. There were some dangerous problems on the streets and the residents needed to know them. Unlike the typical public information methods, model kit for park design was specifically contrived to inform residents of the site, design method and process in a more integrated way. It was assumed that information about design processes and methods would increase the degree of residents participation. Indeed, participants were greatly interested in this tool. But it takes long time to prepare this kind of model kit and it is not flexible enough to accommodate various situations on the field.

\section{Step 2: Design workshop}

After the public information step, the expert team prepared the design workshop for about 100 people including students of the elementary school (5th and 6th graders), which is adjacent to the pocket park site. The aims of the workshop were to include the expected main users to participate in the design process, to reveal their ideas and values, and finally to integrate them to the actual design.

In order to achieve these goals, the expert team made a main participatory tool, called paper kit for park design. It consisted of a base map and some kinds of item sheets, such as trees, benches, and paving patterns. The base map included rich and realistic information of surroundings, and like a blank canvas, participants were encouraged to add their ideas freely onto it. Item sheets were given to 
provide types and ranges of possible choices. On the design workshop, the participants gathered in groups, cut the selected items from the sheets and arranged and pasted the selected items along with small post-it papers describing the reasons of their decision. By observation and monitoring after the workshop, the expert team confirmed that young participants could understand the tool easily.

\section{Step 3: Feedback}

In the participatory design, design developments must be attained by feedback, because participants ideas cannot be reflected on the actual design at once. Through the feedback step, the communication among experts and participants is most important. Traditionally, experts used to visualize their design ideas with drawings, such as plans, elevations, sections and perspectives. However, it is difficult for non-expert participants to understand such traditional drawings made of professional signs and terms. Some people cannot interpret certain symbols, such as scale bars, compasses and various legends. They are rather familiar with and interested in the specific properties such as colour, detail, and texture. Not only designed form or space composition, but they would also want to see what kind of activities and uses can be generated on it. As a result, the participants could understand the design output clearly and discussed it with the expert team more vigorously and precisely.

The city entrusted the park users either individual or groups such as park friends namely Koen Aigokai to maintain their closest local parks. In harmony with the number of urban parks in the city, the number of park groups also increasing. City of Nagoya entrusts the park's caretakers to maintain and improve those parks and networks of green paths. The activities not limited to clean up the parks, safety patrol, create the event for children, make the compost, but also in some local parks they do community gardening by planting and caring flower beds.

\subsection{Discussion}

Learning from Nagoya City where they entrusted the Koen Aigokai in every type of urban parks to be actively involved in the park management. They also have good neighbourly relationship, high level of neighbourhood and park satisfaction, happier and healthier feeling. Park with a high level of community participation has resulted that park more beauty and neat and garden within it has create alternative activities in the park such as gardening, and exploring the flowers and green for park users. Bandung City has potency from its people while most of respondents agreed to participate in park management if existed on their park. The increasing numbers of the ageing society and retirement people who still active should be perceived as the community asset. Local government of Bandung City may entrust and encourage the people into park management. Therefore, it will increase the sense of belonging to their park and create lively neighbourhood.

By giving the chance and opportunity for community participation to manage the park and create their communal plot will be valuable for parks, neighbourhood and the community itself in the future. Parks will become more attractive than before and at the same time enhancing the community.

\section{Conclusions}

This paper explained the characteristics of the three major steps in the participatory design processes. It also explained the specific attributes of the design tools applied to each step. The main purpose was to achieve better communications among residents and experts. Such design tools can play important roles in improving the communication among residents and experts in participatory design. In summary, the main factors toward attractive parks are community participation, support from Local Government by entrusting the people for actively participate in greening activity, and strong community will be in voluntary activity such as holding some events or neighbourhood festival in the park. 


\section{RedWhiteperess Gilobal Conferences Series: Sciences and Technology (GCSST), Volume 3, 2020}

\section{References}

[1] K. Greenhalgh, Liz, Worpole, People, parks \& cities: a guide to current good practice in urban parks : a report for the Department of the Environment, 1st ed. London: HMSO Publications Centre, 1996.

[2] T. A. More, "Factors Affecting the Productivity of Urban Parks," PA: U.S. Department of Agriculture, 1990.

[3] S. Gold, "Nonuse of Neighborhood Parks," J. Am. Plan. Assoc., vol. 38, pp. 369-378, 1972.

[4] M. Francis, "Some Different Meanings Attached to a City Park and Community Gardens," Landsc. J., no. September 1987, 2015.

[5] K. Al-kodmany, "Using Visualization Techniques for Enhancing Public Participation in Planning and Design : Process , Implementation , and Evaluation," vol. 2046, no. September 1999, 2018.

[6] A. Hudson-smith, "Visual Communication in Urban Planning and Urban Design," no. June 1998, 2014.

[7] J. Vines, R. Clarke, P. Wright, J. Mccarthy, and P. Olivier, "Configuring participation : On how we involve people in design Configuring Participation : On How We Involve People In Design Republic of Ireland," no. April 2015, 2013.

[8] Bandung City Hall, "KOTA BANDUNG DALAM ANGKA Bandung Municipality in Figures," Bandung, 2018.

[9] E. L. Phillips, Park: Design and Management. New York: McGraw-Hill, 1996.

[10] G. Hugh, Barton; Marcus, Grant; Richard, Shaping Neighbourhoods: A guide for Health, Sustainability and Vitality. Spon Press, 2006.

[11] W. Nick, The Community Planning Handbook: How people can shape their cities, towns and villages in any part of the world, 1st ed. London: Earthscan, 2000.

[12] Urban Action Network, "Making is a Residents Participation," Seoul, 2004.

[13] Nagoya City Hall, "City of Nagoya." [Online]. Available: http://www.city.nagoya.jp/en/. [Accessed: 10-Nov-2018].

Acknowledgments

We would like to give thanks to Post Graduate Program of Universitas Pendidikan Indonesia for supporting this study. High appreciation to all respondents in Bandung and Nagoya Cities. We thank Koen Aigokai leaders and local government of Nagoya and Bandung cities for valuable data and explanations. 